\title{
A Case Report of Successful Retrieval of Missing
Copper T by Laparoscopic Approach

\author{
K Sowmya $^{1}$, D Shruthi ${ }^{2}$, Nandish Manoli ${ }^{3}$
}

\begin{abstract}
A case of migration of intrauterine contraceptive device (IUCD) into the peritoneal cavity diagnosed following pregnancy is presented here. It had to be retrieved by laparoscopic approach. The complications of lost IUCD are discussed, and the need for regular follow-up post-insertion for an early diagnosis of perforation and its complication is emphasized.

KEY WORDS: Laparoscopy, missing intrauterine contraceptive device, pelvic adhesions
\end{abstract}

\section{Introduction}

Because of the ease of availability, and lowcost intrauterine contraceptive device (IUCD) is the second most common used contraceptive worldwide. ${ }^{[1]}$ One of the reasons for discontinuation rates of $20-40 \%$ is the fear of complications such as excessive bleeding, pain, infection, uterine perforation, and spontaneous expulsion..$^{[2-4]}$ Uterine perforation is one such complication which is rare and occurs in 0.5/1000 insertions..$^{[5]}$ However, it has a potential health risk and is often silent. ${ }^{[5]}$ Health workers need to be aware of this complication and should take necessary precautions while inserting Copper $\mathrm{T}$ and be able to provide prompt diagnosis and treatment in the case of missing IUCD so as to prevent chances of migration of IUCD and prevent bowel and bladder perforation. ${ }^{[6]}$ Here, we present a 25-year-old female, G2P1L1 with previous lower segment Caesarean section (LSCS) with 5.6 weeks with missing Copper T. In our case, the Copper T was successfully removed by the laparoscopic approach.

\section{Case Report}

A 25-year-old female, G2P1L1 with previous LSCS, came to gynecology outpatient department with

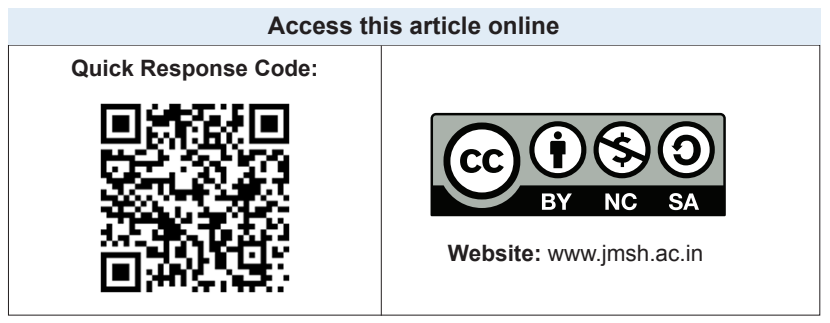

a history of amenorrhea of 1.5 months. She had delivered 8 months back by LSCS and Copper T was inserted after 3 months after delivery by a health worker at her village. After 15 days, after insertion she had menstrual cycles and then cyclically for 3 months after which she came with above complaints. With similar complaints, she went to the district hospital where urine pregnancy test was done and it was tested positive, and ultrasonography (USG) showed a single live intrauterine pregnancy of 5 weeks and 6 days. IUCD could not be traced. $\mathrm{X}$-ray of the pelvis was done (Figure 1) and showed the Copper $\mathrm{T}$ to be in the right iliac fossa and hence she was referred to our hospital.

On examination, her general condition was good, vital signs were normal. Abdomen was soft. On

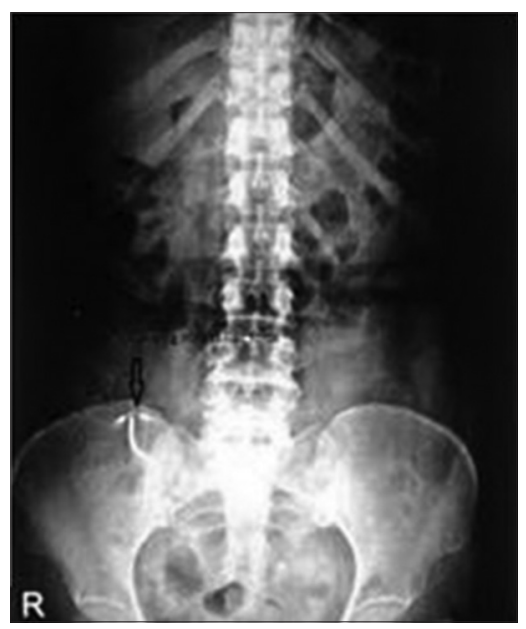

Figure 1: X-ray report showing Copper T in right iliac fossa

${ }^{1}$ Assistant Professor, Department of Obstetrics and Gynaecology, JSS Medical College and Hospital, Mysore, Karnataka, India, ${ }^{2}$ Post-graduate, Department of Obstetrics and Gynaecology, JSS Medical College and Hospital, Mysore, Karnataka, India, ${ }^{3}$ Professor and Unit Head, Department of Obstetrics and Gynaecology, JSS Medical College and Hospital, Mysore, Karnataka, India Address for correspondence:

Dr. K Sowmya, No. 761, E \& F Block, Kuvempunagar, Mysore, Karnataka, India. Phone: +91-9036802610. E-mail: sowsheshu@gmail.com 
speculum examination, IUCD thread was not seen and uterus was enlarged to 6 weeks size on a vaginal examination. An ultrasound was done which suggested single live intrauterine gestation of 5 weeks 6 days. Since the patient was stable and all her investigations carried were within normal limits and patient did not want to continue pregnancy, termination of pregnancy was done by the medical method. After 15 days post-abortion, she was posted for laparoscopic removal of Copper $\mathrm{T}$ (if ne eded for conversion to laparotomy).

\section{Procedure}

During surgery, the uterus left fallopian tube and ovary was free. On the right side the omentum, right tube near the fimbrial end and below it surprisingly the appendix was found to be adherent to each other and to the anterior pelvic wall (Figure 2). After the omental adhesions were carefully removed the thread of the Copper $\mathrm{T}$ was seen, and then the whole of Copper $\mathrm{T}$ was traced between the adhesions and anterior pelvic wall and slowly removed. The following which appendix and peritubal adhesions were released (Figures 3 and 4). Appendix was found to be inflamed and appendectomy was done. Bowels were checked for injury and hemostasis achieved. The patient was kept nil by mouth for $72 \mathrm{~h}$ before being discharged on the $5^{\text {th }}$ day.

\section{Discussion}

Uterine perforation following IUCD is rare and occurs in 0.5-3/1000 insertions but it is a potential health risk. Primary insertion occurs at the time of insertion. ${ }^{[7]}$ Causes include faulty technique, inappropriate timing of insertion, soft uterine wall, wrong measurement of uterocervical length. ${ }^{[8]}$ Secondary uterine perforation is silent and occurs due to slow migration of Copper $\mathrm{T}$ through the uterus with the concurrent bowel peristalsis, spontaneous uterine contractions, bladder contractions. ${ }^{[9]}$ Migrated IUCD may not be discovered until it is found missing or patient become pregnant. Sometimes they may present with pain abdomen or urinary disturbances. Post-insertion women should have follow-up visits as recommended. First, visit should be at the first menstrual period or after 1-month, whichever is earlier. Subsequently after 3 months. Thereafter, once a year for the exclusion of infection, abnormal bleeding, the proper position of Copper T. ${ }^{[10]}$ An IUCD user should be instructed to contact health care provider in case of: (a) IUCD threads cannot be felt, (b) she or her partner can

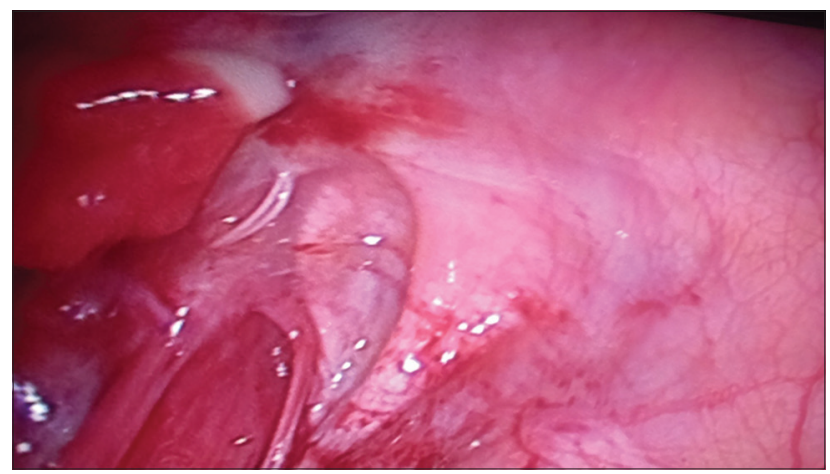

Figure 2: Thread of Copper T seen between adhesions

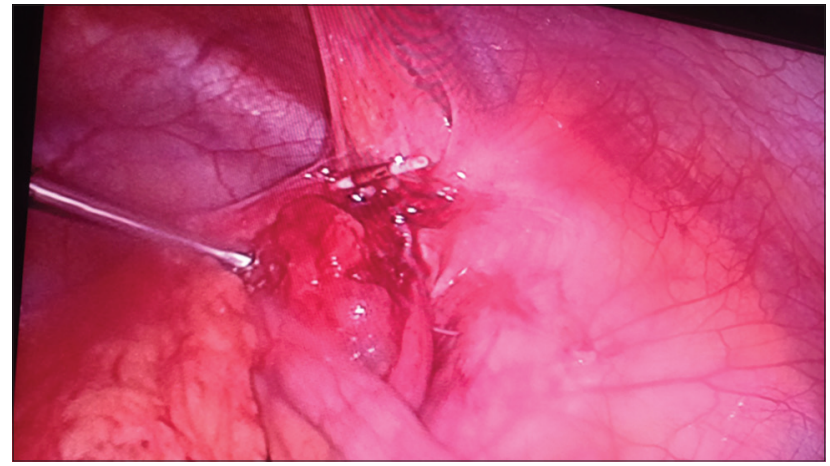

Figure 3: Adhesions being released

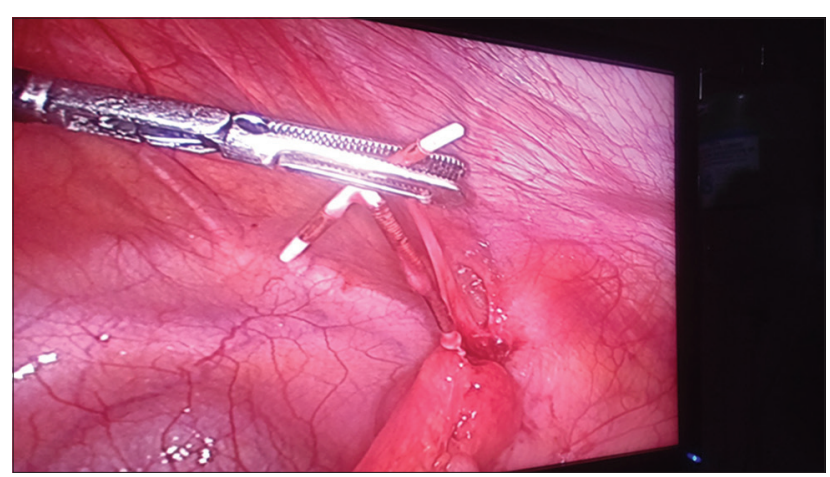

Figure 4: Copper T being completely released

feel the lower end of IUCD, (c) persistent abdominal pain, fever, dyspareunia, unusual vaginal discharge, (d) when she misses periods. All migrated IUCD must be removed as it can enter the peritoneal cavity and cause bowel and bladder perforation and fistula formation.

In our case report, Copper $\mathrm{T}$ was inserted by a health provider at peripheral hospital, and she did not have follow-up and patient came to know about missing Copper T when she was pregnant. 


\section{Conclusion}

All migrated IUCD must be removed as it can cause bowel and bladder perforation, fistula formation. Missing Copper T should be identified using USG, pelvic X-ray/computed tomography scan. In our case X-ray could detect missing Copper T. Removal by hysterolaparoscopy is the best approach. The prevention of complications due to migrated Copper $\mathrm{T}$ is by early detection and regular follow-up.

\section{References}

1. Farouk K, Afridi ZD, Farooq MA, Qureshi IA. Urological complications of intrauterine contraceptive device. JPMI 2007;21:260-5.

2. Bhatnagars MI. A Field Study of IUCD Acceptors in the State of UP. New Delhi: National Institute of Health and Family Welfare; 1988.

3. Savitha HC, Sanjay Kumar C, Gopala Krishna KH, Deepthi HR. Missing copper T with uterine perforation: Two case reports. J Evol Med Dent Sci 2014;3:3640-3.

4. Schaap B. IUD acceptance in rural Madhya Pradesh: Results of acceptors interview. J Fam Welf 1993;39:52-4.

5. Heinberg EM, McCoy TW, Pasic R. The perforated intrauterine device: Endoscopic retrieval. JSLS 2008;12:97-100.

6. Thomalla JV. Perforation of urinary bladder by intrauterine device. Urology 1986;27:260-4.
7. Aoun J, Dines VA, Stovall DW, Mete M, Nelson CB, Gomez-Lobo V. Effects of age, parity, and device type on complications and discontinuation of intrauterine devices. Obstet Gynecol 2014;123:585-92.

8. Toivonen J, Lukkainen T, Allonen H. Protective effect of intrauterine release of levonorgestrel on pelvic infection: Three years' comparative experience of levonorgestrel and copper releasing intrauterine devices. J Obstet Gynaecol 1990;77:261-4.

9. Singh I. Intravesical Cu-T emigration: An atypical and infrequent cause of vesical calculus. Int Urol Nephrol 2007;39:457-9.

10. Guidelines for IUCD Insertion for Medical Officers. New Delhi: Ministry of Health and Family Welfare, Government of India; 2003.

\section{Financial Support: None; Conflict of Interest: None}

How to cite this article: Sowmya K, Shruthi, Manoli N. A case report of successful retrieval of missing Copper T by laparoscopic approach. J Med Sci Health 2016;2(1):37-39.

Date of submission: $12-12-2015$

Date of peer review: 20-01-2016

Date of acceptance: 27-01-2016

Date of publication: 15-02-2016 